\title{
Papers
}

\section{Apoptosis and expression of Bax, Bcl-x, and Bcl-2 apoptotic regulatory proteins in colorectal carcinomas, and associations with p53 genotype/phenotype}

\author{
P M De Angelis, T Stokke, L Thorstensen, R A Lothe, O P F Clausen
}

\begin{abstract}
Aims-Spontaneous apoptosis and expression of the apoptotic regulatory proteins Bax, Bcl-x, and Bcl-2 were investigated in 50 colorectal carcinomas. The p53 genotypes/phenotypes and BAX genotypes were also determined, and possible associations of these with apoptosis and/or with expression of the different apoptotic regulatory proteins were studied.
\end{abstract}

Methods-Terminal deoxynucleotidyl transferase (TdT) mediated dUTP labelling of DNA fragments was used to detect apoptotic tumour cells in sections and peroxidase immunohistochemistry was used to assess protein expression. p53 genotype/phenotype was determined using constant denaturant gel electrophoresis/immunoblotting and bax genotype was determined using polymerase chain reaction based methods.

Results-The distribution of tumour apoptotic indices was bimodal with a natural cut off at $1.0 \%$ (range, $0.0-5.4 \%$ ); the median fraction of apoptotic tumour cells was $\mathbf{0 . 8 \%}$. Tumour apoptosis was not associated significantly with tumour DNA ploidy status. Normal mucosal tissue had less than $0.1 \%$ apoptotic cells. Staining intensities for Bax, Bcl-x, and Bcl-2 were strong; that is, equivalent to or greater than positive normal mucosal cells, in 11 of 50, 20 of 49, and 20 of 48 carcinomas. Frameshift mutations in the bax gene were detected in three of 42 tumours analysed, all of which were DNA diploid, and Bax protein expression in these tumours was absent or very low. Bax, Bcl-x, and Bcl-2 protein expression were not correlated with tumour apoptosis or tumour DNA ploidy status. p53 was expressed in 34 of 50 tumours and p53 gene mutations were detected in 22 of 29 p53 positive tumours analysed. Apoptosis was significantly lower in a greater number of p53 positive tumours than p53 negative tumours. In addition, Bcl-2 protein expression was significantly higher in a greater number of p53 positive tumours com- pared with p53 negative tumours. Bax and Bcl-x protein expression were not significantly associated with p53 phenotypel genotype.

Conclusions-The results indicate that acquisition of a p53 phenotype is associated with lower spontaneous apoptois and higher expression of Bcl-2. The results also suggest that p53 is not a major determinant for Bax expression in colorectal carcinomas in vivo.

(F Clin Pathol: Mol Pathol 1998;51:254-261)

Keywords: apoptosis; colorectal cancer; Bcl-2 related family of proteins; $\mathrm{p} 53$

Apoptosis is necessary for normal tissue homeostasis (the balance between cell proliferation and cell loss) in self-renewing tissues and for the removal of DNA damaged, non-functional, or misplaced cells. ${ }^{1}$ The effector stage of apoptosis, in contrast to the initiation and degradation stages, is subject to regulation by the family of Bcl-2 related proteins, and includes both death agonists (Bax, Bak, Bcl- $\mathrm{x}_{\mathrm{s}}, \mathrm{Bad}, \mathrm{Bik}$, and Hrk) and death antagonists (Bcl-2, Bcl- $\mathrm{x}_{\mathrm{L}}$, Bcl-w, Mcl-1, Bfl-1, Brag-1 and a1). ${ }^{2}$ Bax heterodimerises with $\mathrm{Bcl}-2,{ }^{3} \mathrm{Bcl}-\mathrm{x}_{\mathrm{L}}, \mathrm{Mcl}-1$, and a $1,{ }^{4}$ and also forms homodimers. ${ }^{3}$ The cellular concentrations of death antagonists and agonists (ratio of antagonists to agonists) and the competitive dimerisation between selective pairs of antagonists and agonists appear to determine a cell's susceptibility to apoptosis. ${ }^{25}$

It has been suggested that tumorigenesis might result from deregulation of the biochemical pathways that control apoptosis as well as from deregulation of cell proliferation. ${ }^{6}$ Deregulation of cell death genes leading to overexpression of $\mathrm{Bcl}-2$ or reduction in Bax expression, for example, would alter the Bcl-2:Bax ratio. This could result in resistance to apoptosis induction in DNA damaged cells, ensuring their inappropriate survival and thus increasing the susceptibility to cancer. The expression of some of these death antagonists and agonists has been studied in human tumours. The expression of $\mathrm{Bcl}-2$ was increased in most colorectal adenocarcinomas 
compared with normal mucosal tissue, ${ }^{78}$ and another study showed that spontaneous apoptosis was reduced in colorectal carcinomas that had high Bcl-2 expression compared with tumours with low or absent Bcl-2 expression. ${ }^{9}$ Expression of another death antagonist, $\mathrm{Bcl}-\mathrm{x}_{\mathrm{L}}$, was raised in primary colorectal adenocarcinomas compared with normal mucosal tissue, whereas expression of the cell death agonist Bak was reduced. ${ }^{10}$ In addition, Bax expression was reduced in primary breast tumours and breast cancer cell lines compared with normal breast epithelium and non-malignant epithelial cell lines, and apoptosis could be induced in those cell lines with high Bax expression. ${ }^{11}$ Low Bax expression also correlated significantly with poor prognosis for patients with glottic carcinomas who received radiotherapy as primary treatment. ${ }^{12}$

Apoptosis can be induced in vitro by wild-type p53 through one apoptotic pathway, ${ }^{13}{ }^{14}$ but the mechanism by which this induction occurs is unclear. Wild-type p53 might use transcriptional activation and/or direct protein signalling to initiate apoptosis. ${ }^{15}$ Indeed, p53 has been shown to upregulate BAX and to downregulate BCL-2 $2^{16}$ through direct transactivation of the BAX gene promoter, ${ }^{17}$ and via binding to a negative regulatory element outside of the BCL-2 gene promoter ${ }^{18}$ respectively. Because the p53 gene is mutated in $\sim 50 \%$ of colorectal carcinomas, and because most of the p53 mutations map almost exclusively within the DNA binding domains, ${ }^{19}$ it is likely that mutant p53 proteins can no longer transactivate the genes that are involved in the regulation of apoptosis. This could result in a defective ability to induce apoptosis. ${ }^{19} 20$

In our study, levels of spontaneous apoptosis in 50 colorectal carcinomas were determined using terminal deoxynucleotidyl transferase (TdT) mediated dUTP labelling of DNA fragments to detect apoptotic cells in paraffin wax imbedded sections. The expression of Bax, $\mathrm{Bcl}-\mathrm{x}$, and $\mathrm{Bcl}-2$ in the same tumours was assessed using peroxidase immunohistochemical methods. The p53 genotype and phenotype, and BAX genotype were also determined for these tumours. Expression patterns for Bax, $\mathrm{Bcl}-\mathrm{x}$, and $\mathrm{Bcl}-2$ were compared with each other as well as with tumour apoptosis and the p53 phenotype/genotype.

\section{Materials and methods}

TUMOUR MATERIAL

Fifty surgically removed and previously untreated sporadic colorectal carcinomas and several normal colonic mucosal tissue samples were included in our study. Tumour tissue was obtained immediately after surgery, and pieces were either frozen at $-80^{\circ} \mathrm{C}$ or fixed in $4 \%$ buffered formalin for subsequent embedding in paraffin wax. Thirty one tumours were removed from the left colon or rectum and 14 tumours from the right colon; information regarding tumour site was not available for five tumours.
IMMUNOHISTOCHEMICAL ANALYSES Detection of apoptotic cells in colorectal tumour sections

The ApopTag Plus in situ apoptosis detection kit (peroxidase) (Oncor, Gaithersburg, Maryland, USA) was used to label apoptotic cells in thin $(3 \mu \mathrm{m})$ sections of formalin fixed, paraffin wax embedded colon tumours and normal mucosal samples, following the manufacturer's staining procedure. This detection method ${ }^{21}$ uses TdT to end label DNA fragments (resulting from apoptosis) with dUTP. Both morphologically identifiable, intact apoptotic nuclei and apoptotic bodies can be identified, and possibly pre-apoptotic cells (which lack the characteristic apoptotic morphology) in some systems. Briefly, deparaffinised sections were treated with proteinase $\mathrm{K}(20 \mathrm{ug} / \mathrm{ml})$ for 15 minutes at room temperature before using TdT to label the 3'-OH ends of DNA with digoxigenin labelled nucleotides (one hour incubation at $37^{\circ} \mathrm{C}$ ). The sections were then treated with antidigoxigenin antibody-peroxidase conjugate for 30 minutes at room temperature, stained with diaminylbenzidine (DAB) development solution for 3-6 minutes to produce the characteristic brown colour of positive cells, counterstained with haematoxylin, and mounted.

Tumour sections were examined microscopically and, for each section, several fields were evaluated and at least 1000 cells were scored as apoptotic (strong brown colour) or normal (unstained). Mean and median apoptotic indices were calculated for each tumour. Criteria for assessment of the tumour apoptotic index were as follows: both morphologically apoptotic and pre-apoptotic single cells were counted. Grossly necrotic tumour areas and small clusters of necrotic cells (more than five positive cells in one group) were avoided when counting. Positive cells in the glandular lumina or outside of areas of intact tumour tissue were not counted. It was not possible to determine how many apoptotic cells one phagocytosing tumour cell could represent in areas where tumour cells had phagocytosed a lot of nuclear apoptotic fragments from neighbouring cells. Therefore, each cell with apoptotic fragments was counted as one apoptotic event.

Determination of Bax, Bcl-x, and Bcl-2 expression in tumour sections

The procedure for Bax staining as described by Krajewski and colleagues ${ }^{22}$ was modified to stain 50 tumour sections in parallel for Bax, $\mathrm{Bcl}-\mathrm{x}$, and Bcl-2 proteins. Formalin fixed, paraffin wax embedded tissue sections $(3 \mu \mathrm{m})$ were deparaffinised by two washes in xylene for five minutes each, and then dehydrated in absolute ethanol. The sections were incubated in $3 \%$ (vol $/ \mathrm{vol}) \mathrm{H}_{2} \mathrm{O}_{2}$ in methanol (45 seconds), dehydrated further in ethanol, and washed in phosphate buffered saline (PBS) for five minutes. The sections were then heated in a pressure cooker for five minutes at $116^{\circ} \mathrm{C}$ in $10 \mathrm{mM}$ citric acid buffer ( $\mathrm{pH} \mathrm{6.0)}$, followed by rinsing in lukewarm tap water. They were then washed in Tris buffered saline (TBS), $\mathrm{pH} 7.8$, for five minutes, followed by blocking treatment 
with TNK buffer (100 mM Tris, pH 7.6-7.8, $550 \mathrm{mM} \mathrm{NaCl}, 10 \mathrm{mM} \mathrm{KCl}$ ), which contained $2 \%$ (wt/vol) bovine serum albumin (BSA), $0.1 \%$ Triton X100, and 1\% normal goat serum. Rabbit antihuman Bax, Bcl-x, and Bcl-2 polyclonal antibodies (Santa Cruz Biotechnology, Santa Cruz, California, USA; $1 / 20$ dilution of $100 \mu \mathrm{g} /$ $\mathrm{ml}$ stock made up in TNK buffer) were added and the sections incubated overnight in a humidified chamber placed at $4^{\circ} \mathrm{C}$. The specificities of the antibodies for the Bax, Bcl-x, and $\mathrm{Bcl}-2$ proteins were determined previously by immunoblotting; the antibodies detected proteins with molecular weights of $21 \mathrm{kDa}$ (Bax), $32 \mathrm{kDa}\left(\mathrm{Bcl}-\mathrm{x}_{\mathrm{L}}\right.$ - the anti-apoptotic isoform of $\mathrm{Bcl}-\mathrm{x}$ was the predominant form expressed in colorectal tumours), and $27 \mathrm{kDa}$ (Bcl-2) (data not shown). They were then washed with PBS and incubated for one hour at room temperature with biotinylated goat antirabbit antibody (1/500 in TNK buffer) in a humidified chamber, followed by washing with PBS. Incubation for 30 minutes at room temperature with streptavidin horseradish peroxidase (1/20 in TNK buffer) was then performed, and the sections were then developed in a solution containing $0.06 \% \mathrm{DAB}$ and $0.1 \%$ (vol/vol) $\mathrm{H}_{2} \mathrm{O}_{2}$ made up in TNK buffer (without goat serum, BSA, and Triton X100), counterstained with haematoxylin, and mounted.

Positive cells in tumour sections were stained brown, and the intensities of staining were evaluated independently by two of the authors (OPFC and PMD). Occasional disagreements regarding the visual evaluation of staining intensities were discussed and a consensus reached. A few tumours were selected randomly for restaining and re-evaluation some months after the initial staining/microscopic evaluation to test the reproducibility of both, with consistent results. Normal mucosal cells, muscle cells, nerve cells, and granulocytes also stained positively with these antibodies. Tissue sections that were not treated with the primary antibodies served as negative staining controls for our study. Normal mucosal tissue was scored as 2; tumours with intensity of staining equal to or greater than that seen in normal mucosal tissue were scored as 2 or 3 , respectively. Tumours with intensity of staining lower than that seen in normal mucosal tissue were designated as 1 (or $<1$ ). Tumours with no detectable staining were scored as negative (0). The percentages of positive cells at the observed intensities were also estimated for each section. Staining intensity and the percentage of cells that were positive at that intensity were multiplied to generate a "weighted score" for expression of each protein. Tumours were grouped subsequently according to levels of expression: $<1.0$ (low expression), $\geqslant 1.0$ (moderate/high expression) for the purposes of statistical analysis, with 3.0 being the highest possible weighted score.

MUTATION ANALYSIS OF THE p53 GENE (EXONS 5-8)

In our earlier work, ${ }^{23}{ }^{24}$ we reported p53 mutation analysis of 22 and 28 colorectal tumours respectively, of which eight and 20 are included in this study. Mutation analysis of 22 new tumours was performed by amplification of template DNA followed by product separation using constant denaturant gel electrophoresis $(\mathrm{CDGE})^{25}$ or temporal temperature gel electrophoresis (TTGE) (D-GENE system; BioRad, Hercules, California, USA). ${ }^{26}$ Samples with aberrantly migrating bands detected by CDGE/TTGE were analysed by perpendicular denaturing gradient gel electrophoresis (DGGE) to confirm the mutation. Identification of the exact base change was obtained by sequencing of polymerase chain reaction (PCR) products on an Applied Biosystems 373 DNA sequencer (Rotterdam, The Netherlands) using protocols supplied by the manufacturer. The PCR products were purified on Pharmacia Biotech Microspin Columns (Pharmacia, Uppsala, Sweden) and AmpliTaq DNA polymerase and Dye Terminators (Perkin Elmer, Oslo, Norway) were used in the sequencing reaction. Primers and conditions for the melting gel analyses are described elsewhere. ${ }^{27}$ Minor modifications have been made to this protocol as well as to the establishment of conditions for gel casting of TTGE. ${ }^{28}$ The updated protocol ensures detection of all mutations within the following codons (the whole coding sequence for each exon is given in parentheses): exon 5, codons 126-184 (analysed in two fragments) (126186); exon 6, codons 189-215 (187-224); exon 7, codons 225-260 (225-261); exon 8, codons 265-300 (262-306).

\section{DETERMINATION OF p53 PHENOTYPE}

The p53 phenotype had been determined previously by immunoblotting for most of the colorectal carcinomas in this study and is reported in our earlier studies. ${ }^{23}{ }^{24}$ Eight and 20 tumours from these two studies are included in this study, respectively. An additional 22 new tumours were analysed by immunoblotting, as described in these earlier studies.

MUTATION ANALYSIS OF THE (G) 8 TRACT IN EXON 3 OF THE BAX GENE

Forty two tumours were analysed for somatic frameshift mutations (insertions or deletions) using PCR primers to amplify a 94 base pair region that encompasses the $(\mathrm{G})_{8}$ tract in BAX. The primers used were: 5'-ATC CAG GAT CGA GCA GGG CG-3' and 5'-ACT CGC TCA GCT TCT TGG TG-3'. PCR was carrried out in the presence of $1 \times$ buffer $(10 \mathrm{mM}$ Tris, (pH 8.3), $1.5 \mathrm{mM} \mathrm{MgCl}, 50 \mathrm{mM} \mathrm{KCl}$, $0.01 \%$ BSA), $0.2 \mathrm{mM}$ dATP, $0.2 \mathrm{mM}$ dGTP, $0.2 \mathrm{mM}$ dTTP, $2.5 \mu \mathrm{M}$ dCTP, $0.7 \mu \mathrm{Ci}$ of ${ }^{32} \mathrm{P}-\mathrm{dCTP}(3000 \mathrm{Ci} / \mathrm{mmol}), 300 \mathrm{nM}$ of each of the forward and reverse primer, $0.4 \mathrm{U}$ Taq polymerase (Perkin Elmer) in a volume of $10 \mu \mathrm{l}$. Genomic DNA (50-100 ng) was added and the following PCR programme was applied: $95^{\circ} \mathrm{C}$ for five minutes, followed by 27 cycles of 30 seconds each at $94^{\circ} \mathrm{C}, 75$ seconds at $55^{\circ} \mathrm{C}$, and 15 seconds at $72^{\circ} \mathrm{C}$, with a six minute extension during the last cycle. The PCR products were separated on a denaturing $6.0 \%$ polyacrylamide gel containing $7.7 \mathrm{M}$ 


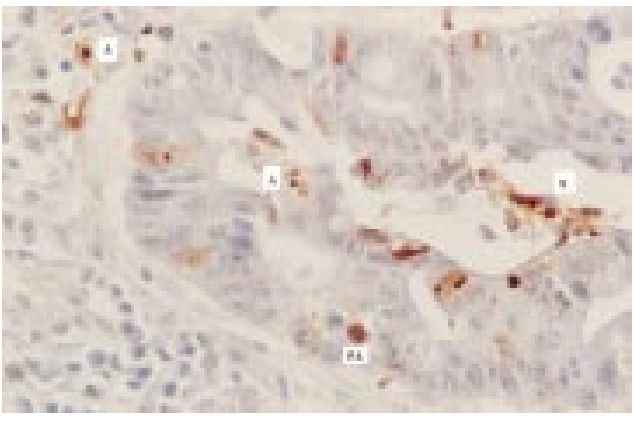

Figure 1 Spontaneous apoptosis in colorectal carcinomas. Colorectal tumour stained for detection of apoptotic cells using the TdT staining method. A, morphologically apoptotic cells; $P A$, pre-apoptotic cells; $N$, small clusters of necrotic debris (magnification, $\times 480$ ).

urea and subjected to autoradiography. HCT116 and LoVo colon carcinoma cell lines (ATCC), both of which have somatic frameshift mutations in the BAX gene, ${ }^{29}$ were used as positive controls. PCR products that showed mobility shifts in the gels were scored as frameshift mutations according to Rampino et al. ${ }^{29}$

DETERMINATION OF TUMOUR DNA PLOIDY

STATUS

Twenty one of the tumours included in our study had been analysed previously for DNA ploidy status, ${ }^{23}$ and an additional 29 tumours were analysed for DNA content using the method outlined in our earlier report. In summary, 33 of 50 tumours were DNA aneuploid (contained stemline with abnormal DNA content) and 16 were DNA diploid; one tumour could not be evaluated.

\section{STATISTICAL ANALYSIS}

Prism and InStat statistical software (Graphpad Software, San Diego, California, USA) were used for the various statistical tests performed in our study. Fisher's exact two tailed $2 \times 2$ contingency tests and $\chi^{2}$ analyses (for larger tables) were used to check for significance of associations ( $\mathrm{p}$ values) between any two parameters. Mann-Whitney two tailed, unpaired, non-parametric tests were used to check for significant differences between two groups of data for a specific parameter. $p$ values $<0.05$ were considered significant.

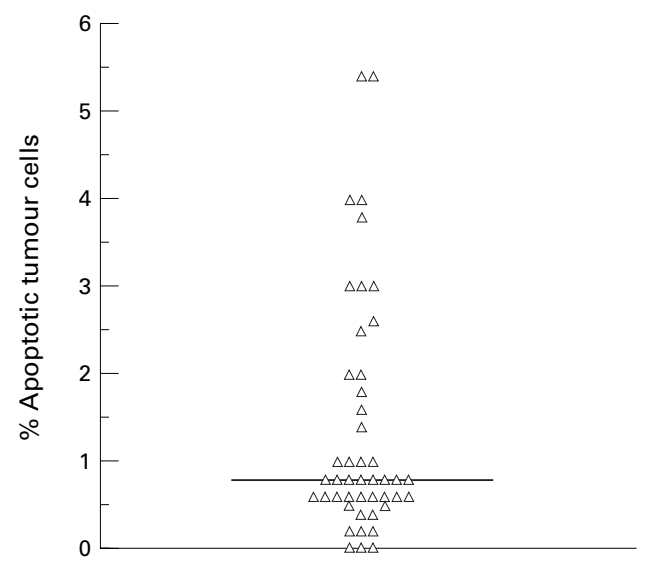

Figure 2 Bimodal scatter distribution of the percentages of spontaneous apoptosis for 46 of 50 untreated colorectal carcinomas. The horizontal line represents the median apoptotic index (0.8). The natural cut off $(1.0 \%)$ divided the tumours into two groups for statistical analysis: one group with percentages of spontaneous apoptosis $<1.0 \%$ and the other with percentages $\geqslant 1.0 \%$.

\section{Results}

SPONTANEOUS APOPTOSIS IN COLORECTAL CARCINOMAS

Most of the single positive tumour cells detected by the TdT method and included in assessments of apoptotic indices were morphologically apoptotic, with characteristic apoptotic bodies and nuclei in various stages of chromatin condensation (fig 1). However, some of the positive cells that were counted were pre-apoptotic, with no distinct nuclear morphological changes by light microscopy. These were relatively few in number. The TdT method also labelled necrotic tumour cells in addition to apoptotic cells. Gross areas of necrosis and small clusters of necrotic debris were avoided when counting. The distribution of tumour apoptosis was bimodal, with a cut off at $1.0 \%$ (range, $0.0-5.4 \%$ ), and the median spontaneous apoptotic index for the tumour group was $0.8 \%$ (fig 2). Twenty seven of 46 tumours had low apoptotic values $(<1.0 \%)$, whereas 19 of 46 had higher values ( $\geqslant 1.0 \%$ ). Tumour apoptotic levels were not associated with tumour DNA ploidy status $(p=1.00)$, because low apoptotic values were seen in over half of both DNA aneuploid and DNA diploid tumours (table 1). Apoptotic cells in normal mucosal tissues were occasionally seen at the surface of the crypts and numbered less than $0.1 \%$.

Table 1 Colorectal tumour apoptotic values and the expression of Bax, Bcl-x, and Bcl-2 in relation to tumour ploidy status and p53 mutation

\begin{tabular}{|c|c|c|c|c|c|c|}
\hline & $\begin{array}{l}\text { Aneuploid } \\
\text { tumours }\end{array}$ & $\begin{array}{l}\text { Diploid } \\
\text { tumours }\end{array}$ & $\begin{array}{l}\text { p53 positive } \\
\text { tumours }\end{array}$ & $\begin{array}{l}\text { p53 negative } \\
\text { tumours }\end{array}$ & $\begin{array}{l}\text { Tumours with p53 } \\
\text { mutation }\end{array}$ & $\begin{array}{l}\text { Tumours without } \\
\text { p53 mutation }\end{array}$ \\
\hline Low apoptotic levels & 17 & 9 & 22 & 5 & 16 & 8 \\
\hline High apoptotic levels & 12 & $\begin{array}{l}7 \\
1.00\end{array}$ & 9 & $p=0.025$ & $p=$ & $\begin{array}{l}10 \\
.055\end{array}$ \\
\hline Low Bax expression & 24 & $\begin{array}{l}1.00 \\
14\end{array}$ & 29 & $\begin{array}{c}10 \\
0\end{array}$ & 19 & 14 \\
\hline High Bax expression & 8 & $\begin{array}{l}3 \\
.725\end{array}$ & 5 & $p=0.140$ & 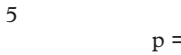 & $\begin{array}{c}4 \\
1.00\end{array}$ \\
\hline Low Bcl-x expression & 18 & 12 & 20 & 10 & 12 & 13 \\
\hline High Bcl-x expression & 13 & $\begin{array}{l}5 \\
.536\end{array}$ & 13 & $\mathrm{p}=\begin{array}{c}6 \\
1.00\end{array}$ & $\mathrm{p}=$ & $\begin{array}{l}5 \\
.208\end{array}$ \\
\hline Low Bcl-2 expression & 17 & 12 & 16 & 13 & 13 & 15 \\
\hline High Bcl-2 expression & 14 & $\begin{array}{l}4 \\
.218\end{array}$ & 17 & $\begin{array}{c}2 \\
p=0.024\end{array}$ & $\mathrm{p}=$ & $\begin{array}{l}3 \\
.096\end{array}$ \\
\hline
\end{tabular}



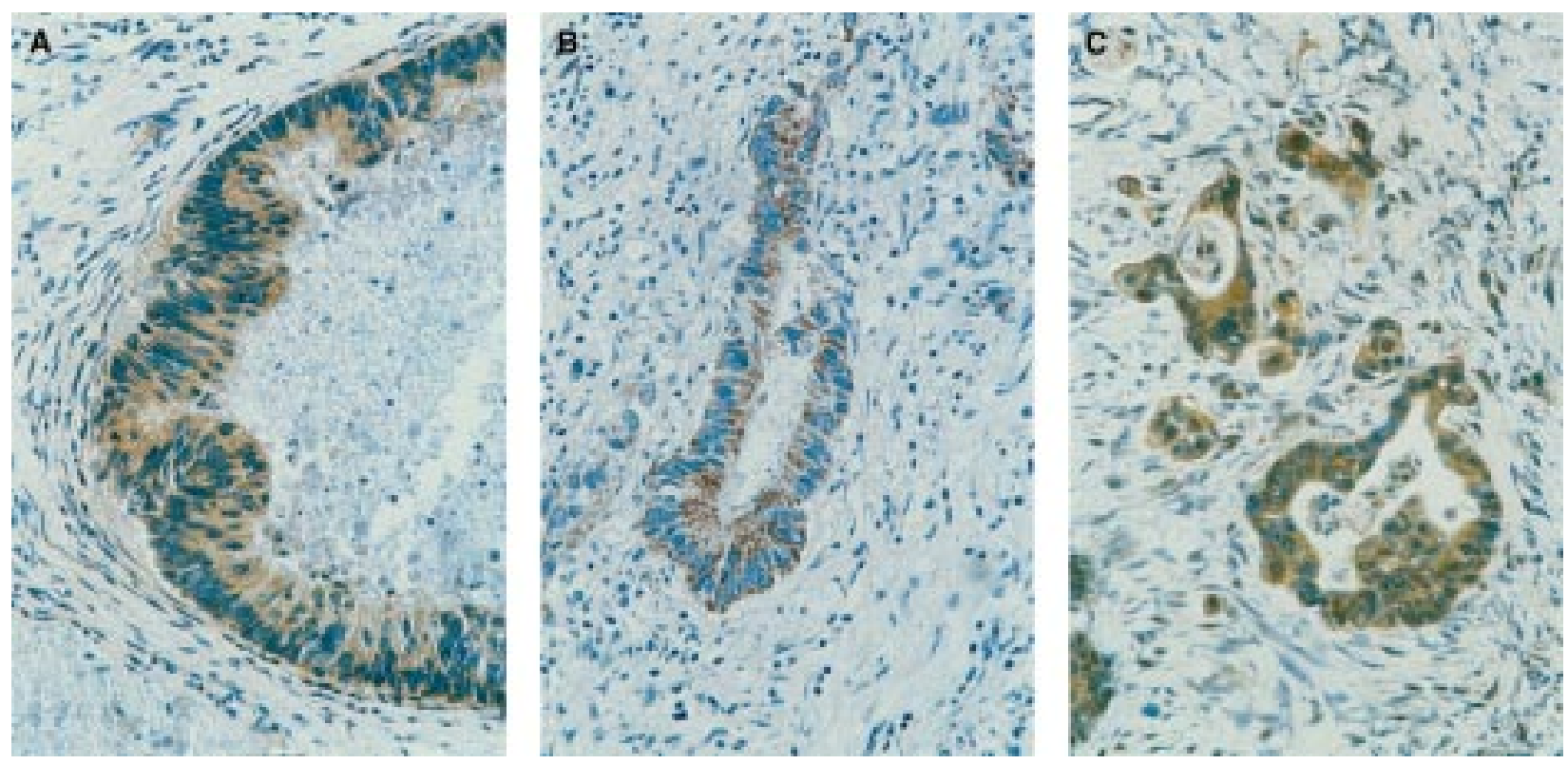

Figure 3 Bax, Bcl-x, and Bcl-2 expression in colorectal carcinomas. Colorectal tumours stained for Bax, Bcl-x, and Bcl-2 proteins using peroxidase immunohistochemistry: $(A)$ strong Bax, (B) strong Bcl-x, and (C) strong Bcl-2 staining in colorectal carcinomas (magnification, $\times 480$ ).

BAX, BCL-X, BCL-2 EXPRESSION, AND BAX MUTATIONS IN COLORECTAL CARCINOMAS Pressure cooking of the sections was effective in unmasking the epitopes of each protein so that the antibodies could bind to them. Positive staining for Bax, Bcl-x, and Bcl-2 in tumour cells was localised to the cytoplasm. In general, Bax and Bcl-2 had a more even and smooth staining pattern, whereas $\mathrm{Bcl}-\mathrm{x}$ was more granular or punctate (fig $3 \mathrm{~A}-\mathrm{C}$ ). Most of the tumours had homogeneous staining; that is, in general, tumours that were scored as positive had the same staining intensity from one area to another. In addition, in most of the tumours that were scored as positive, there were at least $70 \%$ or more tumour cells positive for the specific protein in question. Staining intensities were strong $(\geqslant 1.0)$ in 11 of 50 tumours for $\mathrm{Bax}$, in 20 of 49 evaluable tumours for Bcl-x, and in 20 of 48 evaluable tumours for Bcl-2. The distributions of the weighted expression scores for each protein were the same as for the staining intensities for each protein, with two exceptions. These two tumours had weighted scores for either Bcl-x or Bcl-2 expression that were lower than their staining intensities because of the small percentage of positive cells $(<30 \%)$ at the observed staining intensity, which resulted in low overall expression when the weighted scores were calculated. It should be noted that most of the tumours in our study had low expression (or no detectable expression) of $\mathrm{Bax}, \mathrm{Bcl}-\mathrm{x}$, and $\mathrm{Bcl}-2$ proteins.

Individually, Bax, Bcl-x, and Bcl-2 expression was not associated significantly with tumour apoptosis ( $p=0.768,0.842$, and 0.542 , respectively), because both low and high percentages of spontaneous apoptosis were seen in tumours with low or high concentrations of these proteins. Dual parameter plots of $\mathrm{Bax}$ versus Bcl-2 expression and Bax versus $\mathrm{Bcl}-\mathrm{x}$ expression were made to determine if there was any evident pattern in the way that these proteins associated with each other and with tumour apoptosis. No obvious patterns between apoptosis and Bax, Bcl-x, or Bcl-2 expression, or Bax:Bcl-2 and $\mathrm{Bax}: \mathrm{Bcl}-\mathrm{x}$ ratios were seen (plots not shown). The expression of Bax, Bcl-x, and Bcl-2 was also not associated with tumour DNA ploidy status $(\mathrm{p}=0.725$, 0.536 , and 0.218 , respectively) (table 1 ).

Frameshift mutations of the BAX gene were detected in three of 42 tumours analysed (fig 4). Two of these tumours were negative for Bax expression and had low $(0.4 \%)$ and high $(1.8 \%)$ apoptotic levels (94-29 and 94-34, respectively). The remaining tumour (93-3) had very low Bax expression ( 0.45 weighted score) and low apoptotic levels $(0.6 \%)$. All three tumours with BAX mutations were DNA diploid and localised to the right side of the colon.
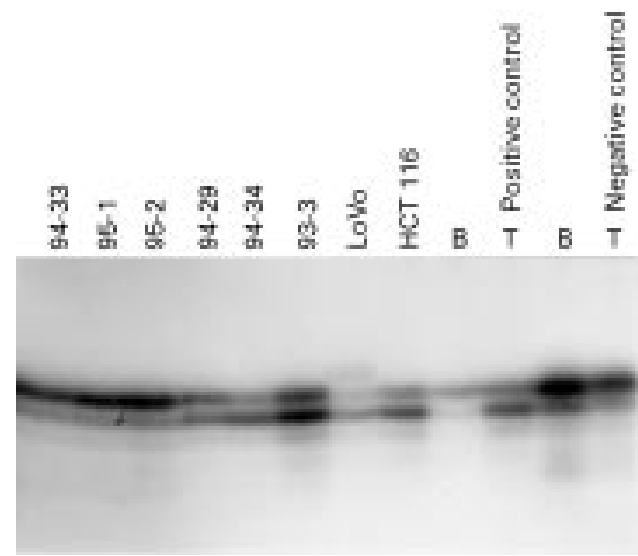

Figure 4 Mutations of the BAX gene in colon carcinomas. Three carcinomas in our series (93-3, 94-29, and 94-34) exhibited the pattern of frameshift mutations caused by deletion in the $(G)_{8}$ repeat in exon 3 of the BAX gene. ${ }^{28}$ The wild-type pattern is shown for three other tumours in our series (94-33, 95-1, and 95-2) and for two blood DNA samples (B). The corresponding tumours (T) to the blood samples are called positive and negative control in the context of bax mutations; both tumours (colorectal carcinomas) are unstable at dinucleotide microsatellite loci, but only one of them (positive) is altered in the $B A X(G)_{8}$ tract. The cell lines LoVo and HCT116 from colon cancers show the expected mutation pattern of the $B A X(G)_{8}$ tract. $^{28}$ 

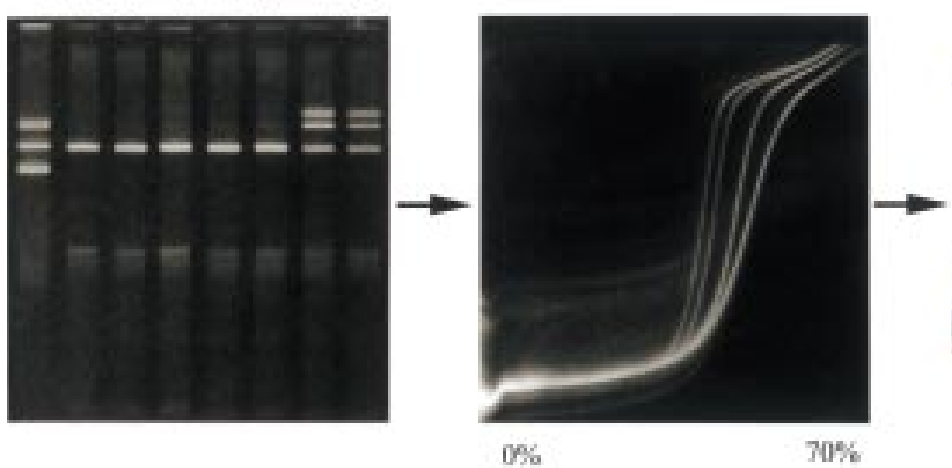

CCAGT TGGNAAAA

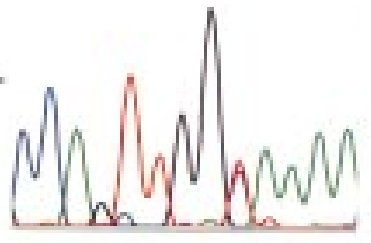

Figure 5 p53 mutation detected in a colon carcinoma. Screening of p53 mutations in exon 5 is illustrated on the left; temporal temperature gel electrophoresis (TTGE) has been used with a 37\% denaturant and a temperature range from $63^{\circ} \mathrm{C}$ to $68^{\circ} \mathrm{C}$. Two mutants (anes 7 and 8), a positive control (ane 1), and five tumours exhibiting only the wild-type fragment (lanes 2-6) are shown. Tumour 93-3, which scored as mutant by TTGE, is confirmed by denaturing gradient gel electrophoresis (DGGE); the gradient from $0 \%$ to $70 \%$ is perpendicular to the electrophoretic run (centre figure). The specific mutation was identified by direct sequencing, as illustrated on the right; the antisense sequence TTG GCA AAA is altered to TTG GTA AAA (codons 134-136) and thereby reveals the missense mutation of codon 135 in the sense thread: TGC to TAC; Cys to Tyr.

p53 EXPRESSION AND P53 MUTATIONS IN

COLORECTAL CARCINOMAS

p53 was expressed in 34 of 50 carcinomas by immunoblotting, and p53 mutations were detected in 22 of 42 tumours examined for

Table 2 p53 mutation spectra in relation to Bax and Bcl-2 expression in colorectal tumours

\begin{tabular}{|c|c|c|c|c|c|c|c|}
\hline \multirow[b]{2}{*}{ Tumour } & \multicolumn{4}{|c|}{ p53 genotype } & \multirow{2}{*}{$\begin{array}{l}\text { p53 } \\
\text { phenotype }\end{array}$} & \multirow{2}{*}{$\begin{array}{l}\text { Bax } \\
\text { score }\end{array}$} & \multirow{2}{*}{$\begin{array}{l}\text { Bcl-2 } \\
\text { score }\end{array}$} \\
\hline & Exon & Codon & Mutation & Amino acid & & & \\
\hline $93-2$ & 5 & 135 & $\mathrm{TGC} \rightarrow \mathrm{TAC}$ & Cys $\rightarrow$ Tyr & + & 0.4 & 2.7 \\
\hline $93-3$ & 5 & 135 & $\mathrm{TGC} \rightarrow \mathrm{TAC}$ & Cys $\rightarrow$ Tyr & + & 0.4 & 1.4 \\
\hline $92-26$ & 5 & 175 & $\mathrm{CGC} \rightarrow \mathrm{CAC}$ & $\mathrm{Arg} \rightarrow \mathrm{His}$ & + & 1.5 & 0.9 \\
\hline $92-1$ & 5 & 175 & $\mathrm{CGC} \rightarrow \mathrm{CAC}$ & Arg $\rightarrow$ His & + & 0.9 & 0.9 \\
\hline $94-14$ & 5 & 176 & $\mathrm{TGC} \rightarrow \mathrm{TAC}$ & Cys $\rightarrow$ Tyr & + & 0.0 & 0.0 \\
\hline $94-6$ & 5 & Unspecified & & & + & 0.0 & 0.0 \\
\hline $94-18$ & 5 & Unspecified & & & + & 0.9 & 2.7 \\
\hline $94-24$ & 5 & Unspecified & & & - & 1.8 & 0.9 \\
\hline $94-30$ & 6 & 195 & $\mathrm{ATC} \rightarrow \mathrm{ACC}$ & $\mathrm{Ile} \rightarrow \mathrm{Thr}$ & + & 0.6 & 0.6 \\
\hline $94-15$ & 6 & 196 & $\mathrm{CGA} \rightarrow \mathrm{TGA}$ & $\mathrm{Arg} \rightarrow$ STOP & - & 0.0 & 0.0 \\
\hline $93-8$ & 6 & 213 & $\mathrm{CGA} \rightarrow \mathrm{TGA}$ & Arg $\rightarrow$ STOP & + & 0.4 & 0.9 \\
\hline $94-32$ & 6 & 213 & $\mathrm{CGA} \rightarrow \mathrm{TGA}$ & $\mathrm{Arg} \rightarrow$ STOP & + & 0.0 & 0.0 \\
\hline $94-21$ & 6 & Unspecified & & & + & 0.4 & 1.8 \\
\hline $95-2$ & 7 & 244 & $\mathrm{GGC} \rightarrow \mathrm{GTC}$ & $\mathrm{Gly} \rightarrow \mathrm{Val}$ & + & 1.2 & 1.8 \\
\hline $93-5$ & 7 & 245 & $\mathrm{GGC} \rightarrow \mathrm{AGC}$ & Gly $\rightarrow$ Ser & + & 1.8 & 1.8 \\
\hline $94-8$ & 7 & 245 & $\mathrm{GGC} \rightarrow \mathrm{AGC}$ & Gly $\rightarrow$ Ser & + & 0.9 & 0.4 \\
\hline $93-6$ & 7 & 248 & $\mathrm{CGG} \rightarrow \mathrm{TGG}$ & Arg $\rightarrow$ Trp & + & 0.4 & 1.5 \\
\hline $93-9$ & 7 & 248 & $\mathrm{CGG} \rightarrow \mathrm{CAG}$ & Arg $\rightarrow$ Gln & + & 0.0 & 1.5 \\
\hline $94-12$ & 7 & 248 & $\mathrm{CGG} \rightarrow \mathrm{TGG}$ & Arg $\rightarrow$ Trp & + & 0.9 & 0.4 \\
\hline $92-29$ & 8 & 273 & $\mathrm{CGT} \rightarrow \mathrm{CAT}$ & Arg $\rightarrow$ His & + & 0.9 & 1.6 \\
\hline $95-1$ & 8 & 273 & $\mathrm{CGT} \rightarrow \mathrm{TGT}$ & Arg $\rightarrow$ Cys & + & 1.8 & 2.7 \\
\hline $92-2$ & 8 & 275 & $\mathrm{TCT} \rightarrow \mathrm{TTT}$ & Cys $\rightarrow$ Phe & + & 0.7 & ND \\
\hline $92-6$ & 8 & 282 & $\mathrm{CGG} \rightarrow \mathrm{TGG}$ & Arg $\rightarrow$ Trp & + & 0.9 & 0.9 \\
\hline $92-5$ & 8 & Unspecified & & & + & 0.9 & 1.5 \\
\hline $92-7$ & & & - & & + & 0.6 & 0.0 \\
\hline $92-28$ & & & - & & + & 0.9 & 1.8 \\
\hline $93-11$ & & & - & & + & 0.0 & 0.4 \\
\hline $94-17$ & & & - & & + & 0.4 & 0.6 \\
\hline $94-19$ & & & - & & + & 0.9 & 0.9 \\
\hline $94-26$ & & & - & & + & 0.2 & 0.0 \\
\hline $94-27$ & & & - & & + & 0.9 & 1.8 \\
\hline $90-7$ & & & - & & - & 1.8 & 0.0 \\
\hline $90-8$ & & & - & & - & 1.8 & 0.9 \\
\hline $92-4$ & & & - & & - & 0.9 & 0.9 \\
\hline $94-1$ & & & - & & - & 1.2 & 0.7 \\
\hline $94-3$ & & & - & & - & 0.9 & 0.8 \\
\hline $94-23$ & & & - & & - & 0.7 & 0.0 \\
\hline $94-25$ & & & - & & - & 1.8 & 0.9 \\
\hline $94-28$ & & & - & & - & 0.9 & 0.9 \\
\hline $94-29$ & & & - & & - & 0.0 & 0.0 \\
\hline $94-33$ & & & - & & - & 0.4 & 1.8 \\
\hline $94-34$ & & & - & & - & 0.0 & 0.4 \\
\hline
\end{tabular}

Values for Bax and Bcl-2 expression are given as weighted scores.

ND, not determined. mutations using TTGE and DGGE. There was a significant association between p53 expression and mutations, because 22 of 29 p53 positive tumours had mutations compared with only two of 13 p53 negative tumours $(p=0.0005)$. The detection of a p53 mutation in one colon carcinoma, 93-3, is shown in fig 5 .

Approximately three quarters of the p53 positive tumours had low levels of spontaneous apoptosis, in contrast to a third of the p53 negative tumours $(\mathrm{p}=0.025)$ (table 1$)$. There was a correspondingly significant association between $\mathrm{p} 53$ genotype and spontaneous tumour apoptosis $(\mathrm{p}=0.055)$, because a greater number of tumours with $\mathrm{p} 53$ mutations had lower percentages of spontaneous apoptosis than tumours without p53 mutations.

RELATIONS BETWEEN P53 PHENOTYPE/GENOTYPE AND BAX, BCL-X, AND BCL-2 EXPRESSION Bax expression was not associated significantly with either $\mathrm{p} 53$ expression or $\mathrm{p} 53$ status $(\mathrm{p}=$ 0.140 and $p=1.00$, respectively) (table 1 ). Five tumours with p53 gene mutations located in exons 5, 7, and 8 had high Bax expression (table 2 ), but the median Bax expression in each exon group $(0.6,0.9,0.9$, respectively) did not differ significantly from the median value seen in tumours without p53 mutations (0.9). Four tumours without p53 mutations also had high Bax expression. Tumours with mutations located in exon 6 had the lowest median Bax expression (0.4); it should be noted from table 2 that this group of tumours included the three tumours with p53 mutations resulting in stop codons, although in two of these cases where stop codons were indicated, p53 protein was detected. One tumour (93-3) with a BAX mutation also had a p53 mutation in exon 5 at codon 135 , whereas the remaining two tumours with BAX mutations had no p53 mutations.

Bcl-x expression was not associated significantly with $\mathrm{p} 53$ phenotype $(\mathrm{p}=1.00)$ or genotype $(\mathrm{p}=0.208)($ table 1$)$. 
Bcl-2 expression was associated significantly with p53 phenotype, because more p53 positive tumours had high Bcl-2 expression than p53 negative tumours $(p=0.024)$. A trend towards association between raised $\mathrm{Bcl}-2$ expression and p53 mutant genotype was seen $(\mathrm{p}=0.096)$ (table 1). Colorectal tumours with p53 gene mutations located in exons 7 and 8 had the highest median levels of Bcl-2 expression (1.5 and 1.55 , respectively) compared with tumours without mutations (median, 0.75) (summarised in table 2). Tumours with p 53 gene mutations in codons 5 and 6 had median values of Bcl-2 expression of 0.9 and 0.6 , respectively, mostly similar to that seen in wild-type tumours.

\section{Discussion}

Single colorectal tumour cells labelled by the TdT apoptosis detection technique were assumed to be apoptotic. Most of these had characteristic morphological features of apoptotic cells, but small numbers of positive, single cells lacking characteristic apoptotic morphology were also seen. These were termed preapoptotic cells and were also included in tumour apoptotic indices. Necrotic areas of tumours and small clusters of necrotic cells also stained positively with the TdT end labelling technique, but it was possible to avoid these when counting. Tumour cells that had phagocytosed the nuclear apoptotic fragments of neighbouring cells were scored as one apoptotic event because it was not possible to determine how many apoptotic cells one phagocytosing tumour cell could represent. Using these criteria, it was possible to obtain a reliable estimate of the apoptotic capacity of each tumour. Two groups of colorectal tumours with differing percentages of spontaneous apoptosis were evident from the bimodal distribution of tumour apoptosis. The major tumour group had less than $1.0 \%$ apoptotic cells, whereas the smaller group had higher levels of spontaneous apoptosis, ranging from $1.0 \%$ to $5.4 \%$. Sinicrope and colleagues ${ }^{9}$ reported apoptotic values in colorectal tumours ranging from $0.2 \%$ to $7.0 \%$, consistent with our results. Recent studies have also reported similar levels of apoptosis in colorectal $^{30}$ and breast ${ }^{31}$ tumours. Tumour apoptotic levels were not associated with tumour DNA ploidy status. In fact, most DNA diploid and aneuploid tumours had low apoptotic levels, which implies that deregulation of apoptosis occurs in both groups of tumours, although the mechanisms whereby deregulation is effected might be different. Colorectal tumours with a positive p53 phenotype and mutant p53 genotype had lower apoptotic indices compared with tumours with a negative p53 phenotype and no p53 mutations. Bax, Bcl-x, and Bcl-2 expression were not associated significantly with tumour apoptosis or tumour ploidy status. The lack of association of apoptotic levels with expression of these proteins might be because other proteins (such as Bak, Bad, Mcl-1, or others that are at present unknown) might be as (or more) important in terms of their effects on apoptosis.

$\mathrm{Bax}, \mathrm{Bcl}-\mathrm{x}$, and $\mathrm{Bcl}-2$ proteins were localised to the cytoplasm in tumour cells, consistent with the results of previous studies describing the cytoplasmic localisation of staining for each of these proteins. ${ }^{9} 10233233$ Bax expression was low in approximately three quarters of the tumours examined in our study; likewise, $\mathrm{Bcl}-\mathrm{x}$ and $\mathrm{Bcl}-2$ expression was low in over half of the same tumour group. In contrast, Krajewska and colleagues $^{10}$ reported low Bcl-x values in $40 \%$ and low Bcl-2 levels in $90 \%$ of colorectal carcinomas, whereas Bax expression was reduced in only $23 \%$ of the carcinomas, compared with the staining intensity seen in positive, normal mucosal cells. The low Bcl-2 expression could be the result of loss of $18 \mathrm{q},{ }^{34}$ leading to allelic loss of the BCL-2 gene locus (18q21.3) ${ }^{35}$ in most colorectal tumours. Genetic changes affecting the BAX and BCL-x genes might also explain the expression patterns seen, at least for some tumours. The BAX gene is located on chromosome 19 (locus 19q13.3-13.4), which has not been reported to be deleted in colorectal tumours. However, somatic frameshift mutations in the $(G)_{8}$ tract of exon 3 of the BAX gene have been reported in $50 \%$ of microsatellite unstable colorectal carcinomas. ${ }^{29}$ Frameshift mutations of the BAX gene were detected in three of 42 colorectal tumours in our study. This is in accordance with Rampino and colleagues ${ }^{29}$ because $15-20 \%$ of all sporadic carcinomas are microsatellite unstable (that would mean six to eight tumours in our study), and half of these are expected to be affected at the BAX repeat locus. Bax expression in tumours with BAX frameshift mutations was absent (two tumours) or very low (one tumour), which suggests that these mutations result in a reduced Bax expression pattern in vivo. The low number of tumours with these BAX mutations cannot account for the overall low Bax expression seen in most colorectal tumours in our study, but it appears that these BAX mutations do result in the loss or reduction of Bax expression in those tumours which have them. A missense mutation in the $\mathrm{BH} 1$ domain (necessary for heterodimerisation with other Bcl-2 family members) of the BAX gene has been reported in Daudi cells, and two BAX missense mutations were seen in another leukaemia cell line, HPB-ALL, ${ }^{36}$ but Bax expression was not reduced or lost in these cell lines. It is at present unknown if there are mutations in the $\mathrm{BH} 1$ domain and/or in other exons of the BAX gene. The BCL-x gene is located on chromosome 20, which is often amplified in colorectal cancer $^{37}$ (De Angelis et al, submitted, 1998), but whether the specific BCL-x gene locus (20q12) is amplified or altered, and if so, the effect on expression pattern, remain unknown.

The p53 gene is mutated in approximately one half of colorectal tumours, and most of the mutations map almost exclusively within its DNA binding domains. ${ }^{19}$ If the apoptotic pathway in colorectal cancer is assumed to be p53 mediated, then deregulation of this pathway has already occurred upstream of BAX and BCL-2 in the case of p53 gene mutation, because it is unlikely that mutant $\mathrm{p} 53$ proteins can bind to the genes (BAX and BCL-2) that are involved in the regulation of apoptosis. Thus, high expression of Bcl-2 and low expression of Bax could be expected in some human tumours with mutant p53 proteins. ${ }^{16}$ The p53 positive tumours in our study had significantly higher 
Bcl-2 expression and lower spontaneous apoptosis compared with p53 negative tumours. Thus, the trend revealed in our study is that acquisition of a p53 phenotype is associated both with higher $\mathrm{Bcl}-2$ expression and lower spontaneous apoptosis in colorectal tumours. Tumours with p53 mutations (especially localised to exons 7 and 8) tended to have raised Bcl-2 expression compared with tumours without mutations. The association between p 53 and Bcl-2 expression became significant after the inclusion of two tumours with detectable p53 expression but no gene mutation. Whether there is a causal relation between p53 accumulation/ p53 mutation and increased Bcl-2 expression is unknown. Interestingly, a recent study ${ }^{38}$ showed that one mutant $\mathrm{p} 53$ protein (mutation at codon 175, Arg to His) actually downregulated Bcl-2 expression in MCF-7 breast cancer cells as efficiently as wild-type p53. Two tumours in our study with the same mutant $\mathrm{p} 53$ protein had low expression of $\mathrm{Bcl}-2$, suggesting that this particular mutant p53 might also downregulate $\mathrm{Bcl}-2$ expression in colorectal tumours.

In general, Bax expression was low for most of the colorectal tumours in our study, irrespective of p53 phenotype. Thus, p53 does not appear to be a major determining factor for Bax expression in colorectal carcinomas in vivo. Mutant p53 protein $181 \mathrm{~L}$ has been reported to transactivate the BAX promoter in vitro, ${ }^{20}$ whereas other mutant proteins tested (p53143Ala, 173L, 175P) failed to do so. ${ }^{19}{ }^{20}$ Five tumours in our series had mutant $\mathrm{p} 53$ proteins and raised Bax expression, and one tumour had a mutant p53 $175 \mathrm{H}$ protein. Because this mutant p53 175 protein differs from the one reported that fails to transactivate the BAX promoter, we are not able to draw any conclusions regarding its possible role in BAX regulation. In addition, functional studies are necessary to establish a possible causal relationship between specific mutant p53 proteins and Bax expression. It is concluded that there might be other proteins in colorectal tumours that can regulate the BAX gene but which are at present unknown.

The authors wish to thank Dr E Trondsen of the surgical department, Akershus Hospital, Oslo, Norway, for providing colorectal tumour and mucosal specimens. A R Schjølberg, G Gulbrandsen, and M Hektoen are acknowledged for excellent technical assistance. This work was supported by the Norwegian Cancer Society.

1 Jacobson MD, Weil M, Raff MC. Programmed cell death in animal development. Cell 1997;88:347-54.

2 Kroemer G. The proto-oncogene $\mathrm{Bcl}-2$ and its role in regulating apoptosis. Nat Med 1997;3:614-20.

3 Oltvai ZN, Milliman CL, Korsmeyer SJ. Bcl-2 heterodimerizes in vivo with a conserved homolog, Bax, that accelerates izes in vivo with a conserved homolog, Bax,

4 Sedlak TW, Oltvai ZN, Yang E, et al. Multiple Bcl-2 family Sedlak TW, Oltvai ZN, Yang E, et al. Multiple Bcl-2 family
members demonstrate selective dimerizations with Bax. Proc Natl Acad Sci USA 1995;92:7834-8.

5 Yang E, Korsmeyer SJ. Molecular thanatopsis: a discourse on the BCL2 family and cell death. Blood 1996;88:386-401.

6 Williams GT, Smith CA. Molecular regulation of apoptosis: genetic controls on cell death. Cell 1993;74:777-9.

7 Hague A, Moorghen M, Hicks D, et al. BCL-2 expression in human colorectal adenomas and carcinomas. Oncogene 1994;9:3367-70.

8 Bronner MP, Culin C, Reed JC, et al. The bcl-2 protooncogene and the gastrointestinal epithelial tumor progression model. Am 7 Pathol 1995;146:20-6.

9 Sinicrope FA, Ruan SB, Cleary KR, et al. bcl-2 and p53 oncoprotein expression during colorectal tumorigenesis. Cancer Res 1995;55:237-24.

10 Krajewska M, Moss SF, Krajewski S, et al. Elevated expression of Bcl-X and reduced Bak in primary colorectal adenocarcinomas. Cancer Res 1996;56:2422-7.
11 Bargou RC, Daniel PT, Mapara MY, et al. Expression of the bcl-2 gene family in normal and malignant breast tissue: low bax-a expression in tumor cells correlates with resistance towards apoptosis. Int $\mathcal{F}$ Cancer 1995;60:854-9.

12 Xie X, De Angelis P, Clausen OPF, et al. Bax expression has prognostic significance which is enhanced when combined with AgNOR counts in glottic carcinomas. Br 7 Cancer with AgNOR cour

13 Yonish-Rouach E, Resnitzky D, Lotem J, et al. Wild-type p53 nduces apoptosis of myeloid leukaemic cells that is inhibited by interleukin-6. Nature 1991;352:345-7.

14 Shaw P, Bovey R, Tardy S, et al. Induction of apoptosis by wild-type $\mathrm{p} 53$ in a human colon tumor-derived cell line. Proc Natl Acad Sci USA 1992;89:4495-9.

15 Levine A. p53, the cellular gatekeeper for growth and division. Cell 1997;88:323-31.

16 Miyashita T, Krajewski S, Krajewska M, et al. Tumor suppressor p53 is a regulator of bcl-2 and bax gene expression in vitro and in vivo. Oncogene 1994;9:1799-805.

17 Miyashita T, Reed J. Tumor suppressor p53 is a direct transcriptional activator of the human bax gene. Cell 1995;80:293-9.

18 Miyashita T, Harigai $M$, Hanada $M$, et al. Identification of a p53-dependent negative response element in the bcl-2 gene. Cancer Res 1994;54:3131-5.

19 Friedlander P, Haupt Y, Prives C, et al. A mutant p53 that discriminates between p53-responsive genes cannot induce apoptosis. Mol Cell Biol 1996;16:4961-71.

20 Ludvig RL, Bates S, Vousden KH. Differential activation of target cellular promoters by p53 mutants with impaired apoptotic function. Mol Cell Biol 1996;16:4952-60.

21 Gavrieli Y, Sherman Y, Ben-Sasson SA. Identification of programmed cell death in situ via specific labeling of nuclear DNA fragmentation. F Cell Biol 1992;119:493-501.

22 Krajewski S, Krajewska M, Shabaik A, et al. Immunohistochemical determination of in vivo distribution of Bax, a dominant inhibitor of Bcl-2. Am F Pathol 1994;145:1323-36.

23 De Angelis P, Stokke T, Smedshammer L, et al. P-glycoprotein is not expressed in a majority of colorectal carcinomas and is not regulated by mutant $\mathrm{p} 53$ in vivo. $\mathrm{Br} \mathcal{F}$ Cancer 1995;72:307-11.

24 De Angelis, P, Stokke, T, Smedshammer L, et al. p53 expression is associated with a high degree of tumor DNA aneuploidy and incidence of p53 gene mutation, and is localized to the aneuploid component in colorectal carcinomas. Int F Oncol 1993;3:305-12.

25 Hovig E, Smith-Sørensen B, Brøgger A, et al. Constant denaturant gel electrophoresis, a modification of denaturing gradient gel electrophoresis, in mutation detection. Mutat Res 1991;262:63-71.

26 Børresen-Dale A-L, Lystad S, Langerød A. Temporal temperature gradient gel electrophoresis (TTGE) compared with denaturing gradient gel electrophoresis (DGGE) and constant denaturant gel electrophoresis (CDGE) in mutation screening. Bioradiation 1997;95:12-13.

27 Andersen TI, Børresen A-L. Alterations of the TP53 gene as a potential prognostic marker in breast carcinomas. Diagn Mol Pathol 1995;4:203-11.

28 Børreson-Dale A-L, Lystad S, Langerød A. Temporal temperature gradient gel electrophoresis on the dcode system. Bioradiations 1997;99:12-13.

29 Rampino N, Yamamoto H, Ionov Y, et al. Somatic frameshift mutations in the BAX gene in colon cancers of the microsatellite mutator phenotype. Science 1997;275:967-9.

30 Baretton GB, Diebold J, Christoforis G, et al. Apoptosis and immunohistochemical bcl-2 expression in colorectal adenomas and carcinomas. Aspects of carcinogenesis and prognostic significance. Cancer 1996;77:255-64.

31 van de Schepop HAM, De Jong JS, van Diest PJ, et al. Counting of apoptotic cells: a methodological study in invasive breast cancer. F Clin Pathol: Mol Pathol 1996;49:M214-17.

32 Krajewski S, Krajewska M, Shabaik A, et al. Immunohistochemical analysis of in vivo patterns of Bcl-X expression. Cancer Res 1994;54:5501-7.

33 Merritt AJ, Potten CS, Watson AJM, et al. Differential expression of bcl-2 in intestinal epithelia. Correlation with attenuation of apoptosis in colonic crypts and the incidence of colonic neoplasia. f Cell Sci 1995; 108:2261-71.

34 Jen J, Kim H, Piantadosi S, et al. Allelic loss of chromosome $18 \mathrm{q}$ and the prognosis in colorectal cancer. $N$ Engl f Med 1994;331:213-21.

35 Ayhan A, Yasui W, Yokozaki H, et al. Loss of heterozygosity at the bcl-2 gene locus and expression of bcl-2 in human gastric and colorectal carcinomas. Fpn F Cancer Res 1994;85:584-

36 Meijerink JPP, Smetsers TFCM, Sloetjes AW, et al. Bax mutations in cell lines derived from hematological malignancies. Leukemia 1995;9:1828-32.

37 Ried T, Knutzen R, Steinbeck R, et al. Comparative genomic hybridization reveals a specific pattern of chromosomal gains and losses during the genesis of colorectal tumors. Genes Chromosomes Cancer 1996;15:234-45.

38 Haldar S, Negrini M, Monne M, et al. Down-regulation of bcl-2 by p53 in breast cancer cells. Cancer Res 1994;54: 2095-7. Dye terminators. 